\title{
RENAL EFFICIENCY TESTS.
}

\author{
By MONTAGUE MAIZELS, M.D., M.R.C.P., \\ Clinical Pathologist, University College Hospital.
}

In the investigation of renal function, a careful clinical examination is of the first importance. Secondly, it is necessary to examine the urine, and in certain instances also, to perform various special tests for the direct demonstration of deficient renal excretion.

\section{The Urine.}

Assuming that the intake of fluid is normal, a diminished daily excretion of urine unexplained by diarrhœa, vomiting or excessive sweating, will suggest the possibility of some form of renal damage, in which event œdema may be present. Such findings are met with in acute nephritis, in chronic hydræmic nephritis and also when inefficiency results from a deficient circulation through the kidneys such as occurs in cardiac failure or from any condition where severe dehydration is present.

Persistent polyuria, on the other hand, with urine of low specific gravity, will suggest the possibility of chronic azotæmic nephritis, and this diagnosis will be confirmed by the demonstration of high blood pressure, cardiac enlargement, nitrogen retention and the presence of a trace of albumin, and perhaps a few casts, in the urine. In chronic nephritis, the nocturnal urine exceeds in volume that passed by day, so that the patient may have to rise and micturate several times during the night. Normally, the volume of night urine is much less than that of the day urine.

\section{Proteinuria.}

A damaged kidney may permit plasma proteins to leak from the blood into the urine. As plasma albumin has a smaller molecule than globulin, it leaks more easily, hence urine protein consists very largely of albumin. Albuminuria in the absence of pus and blood always suggests the possibility of renal disease. If pus and blood are present, some protein will always be associated, but if the urine is only slightly cloudy with pus, or faintly tinged with blood, not more than a trace of protein will be found. If, therefore, more than one or two parts per thousand are detected, the kidneys are probably involved simultaneously-whatever the nature of the lesion causing pyuria or hæmaturia. Thus pyuria, with a trace of albumin, suggests cystitis, pyelitis or a mild infective lesion of the kidney; moderate pyuria with much albuminuria suggests the possibility of pyelonephritis, or else of pyelitis with an independent nephritis.

Albuminuria also occurs not infrequently in apparently healthy individuals. This will be considered again later.

\section{Blood.}

Blood in the urine may result from a lesion of the urinary tract or of the kidney, or from some general disorder like purpura or scurvy. In nephritis, albuminuria is generally in excess of what might be anticipated from the blood present, although in hæmorrhagic nephritis this may not be at all obvious and casts may be few. This form of nephritis is not uncommon in young children and is difficult to distinguish from other types of hæmaturia. 
In hydræmic nephritis, relatively little blood is found in the urine, and in azotæmic nephritis red cells are few or absent.

\section{Casts.}

Casts are indicative of renal damage, whether temporary, as in the acute fevers or cardiac failure, or permanent as in chronic nephritis. Occasionally a few hyaline casts are found in the urine of apparently normal people.

\section{Special tests for Renal Function.}

In so far as it is the function of the kidney to remove certain substances from the blood and excrete them in the urine, any excess of these substances in the blood may be used as a measure of renal inefficiency. Similarly, a deficiency of such substances in the urine may also be used as an index of renal function. Such renal tests are employed in the diagnosis, prognosis and treatment of medical and surgical conditions, and it must be remembered that no evidence of renal failure appears until from one half to two-thirds of the total kidney tissue has ceased to function, and that even under conditions of widespread destruction, one function may be maintained, while another has almost entirely lapsed.

The two chief tests employed are the Urea Concentration test, and the estimation of the blood urea.

The urea concentration test measures the ability of the kidneys to excrete urea after a standard dose of urea has been given.

I5 grammes of urea in Ioo ccs. of water are administered to the patient who has taken neither food nor drink for twelve hours. The bladder is emptied before, and one, two and three hours after the administration. The volume of the urine samples is measured and the contents of urea estimated. If the urea is above 2.5 per cent. in any single specimen the test is satisfactory; if between 2 and 2.5 per cent. the result is ambiguous, while if the urea is below 2 per cent. in every specimen, the kidneys are inefficient. The last statement, however, must be modified, for if the urea administered evokes diuresis, no significance can be attached to low figures. Diuresis is deemed to occur when the one hour specimen exceeds I2O ccs., or the two or three hour specimen exceeds roo ccs. This is usually due to imperfect preparation; the patient having taken fluid during the preparatory period.

Blood Urea.-This is usually between 20 and $35 \mathrm{~m}$. gms. per cent., although values up to $40 \mathrm{~m}$.gms. may be considered normal. Indeed, figures up to 50 m.gms. per cent. may be encountered in the elderly, and sometimes in younger people who have abstained from fluids over long periods-particularly in hot weather. Figures over $50 \mathrm{~m} . \mathrm{gms}$. per cent. are abnormal. On the other hand, the prolonged use of a low protein diet may lower the blood urea to normal, even when renal excretion is deficient.

Efforts have been made to correlate the levels of blood urea and urine urea, the most important of these being the urea clearance test of Van Slyke and his coworkers. Renal efficiency is measured by the rate at which blood is cleared of urea by the kidneys, or, in other words, the correlation between the amount of urea excreted in unit time, and the level of blood urea. The standard clearance, which is the measure of renal efficiency, equals $U / B \times \sqrt{V}$, where $U$ equals the urine urea, $\mathrm{B}$ the blood urea, and $\mathrm{V}$ is the number of ccs. of urine excreted per 
minute. The bladder having been emptied, urine samples are collected at the ends of two successive hour periods, and the blood urea is estimated at the end of the first hour. From these data, U, B and V are obtained. According to Van Slyke, the clearance test is a much more sensitive index of kidney function than the blood urea, for when the clearance is reduced to between 20 and 40 per cent., blood urea is normal in more than half the cases, and not until the clearance is reduced to 20 per cent. of the normal does the blood urea shew constant elevation. This view is amply confirmed by the results of other workers, and it is probable that Van Slyke's test should be preferred to investigations which are directed to the estimation of blood urea or urine urea separately. (Details of Van Slyke's Maximum Clearance and Standard Clearance Tests will be found in Peters and Van Slyke's "Quantitative Clinical Chemistry," published by Ballière, Tindall \& Cox.)

The retention of inorganic phosphate and of cholesterol are also used as measures of renal function, as is the ability of the kidney to excrete dyestuffs like phenol-sulphone-phthalein.

\section{Uses of Renal Tests.}

The diagnosis of Albuminuria.-In examining schoolchildren or candidates for life insurance, a certain number of cases with albuminuria will be encountered, and in these instances it is necessary to exclude renal disease. If the blood pressure $\overline{0}$ and heart-size are normal, if the urine is free from blood and casts, and if the urea concentration test is satisfactory, the albuminuria is probably not significant. If possible, however, a blood urea estimation should also be carried out, and if this is below $40 \mathrm{~m} . \mathrm{gms}$. per cent. renal disease is improbable.

Sometimes casts are detected in the urine of apparently normal people. Granular casts are pathological, but a few hyaline casts are probably not significant, provided that all the other findings are normal. Occasionally, one encounters both hyaline casts and traces of albumin in the urine, and such cases must always be suspect. If the physical signs and chemical tests are satisfactory the case should be observed over a period of a year or more, and, in the absence of further developments, the prognosis is probably good. In difficult cases of this type, Van Slyke's clearance test should be used, while estimation of the blood cholesterol may help; values above $200 \mathrm{~m}$.gms. per cent., supporting a diagnosis of organic renal disease.

In orthostatic albuminuria (not uncommon in childhood and adolescence) the marked influence of posture will be apparent. As, however, all forms of albuminuria may be decreased by recumbency, it is desirable to conduct renal efficiency tests, including urea clearance and blood cholesterol, on all these cases.

In hyperpiesia, signs of renal failure may be late, and in these cases the prognosis is fair. But if albuminuria is detected, and especially if efficiency tests are unsatisfactory the prognosis is not so good.

Nephritis.-In acute nephritis the blood urea may be quite normal, or it may be raised. In the early stage, a raised blood urea need cause no special anxiety, but if after two months the blood urea fails to fall or even rises, there is a distinct possibility that the malady is becoming chronic. 
In nephrosis (hydræmic, subacute or chronic parenchymatous nephritis) the blood urea is usually not raised and the urea concentration test is normal. But although the concentration may be normal, the absolute amount of urea excreted after the ingestion of fifteen grammes is sometimes diminished, and Van Slyke's standard clearance test may be low: These cases often shew œedema, and should urea excretion be adequate, urea may be given as such or in the form of a high protein diet, with the object of producing diuresis. The results of such treatment are sometimes very satisfactory. Certainly, in these cases there is no call for any restriction in the diet for, as we have seen, the blood urea is usually normal, while estimation of the plasma proteins shews that they, and especially the albumin fraction are greatly diminished.

In azotæmic (chronic interstitial) nephritis, œdema is slight or absent; blood pressure is high, and the heart enlarged. Traces of albumin are usually found in the urine, but sometimes it is absent altogether for long periods. The blood urea is usually raised to more than $60 \mathrm{~m}$.gms. per cent., and its level has a prognostic significance, for if consistently above $150 \mathrm{~m}$.gms. per cent. the patient is not likely to survive many months-although striking exceptions are encountered now and then. In the great majority of uræmic patients values above $100 \mathrm{~m}$.gms. per cent. are common, and values exceeding $400 \mathrm{~m} . \mathrm{gms}$, per cent. are not infrequent. In coma of unknown origin, values above IOO m.gms. render uræmia likely, and values above I50 m.gms. per cent. probable, for although the blood urea may be raised as a terminal event in any malady, high levels of the order indicated are not often attained.

The retained urea is not of itself responsible for uræmic poisoning, but it is probably an index of other and more toxic substances retained in the blood. On the other hand, there is no evidence that a low protein diet is specially beneficial to azotæmic patients, nor is it to be thought that life will be so long maintained on a diet which contains less than the basal requirements of protein.

The inorganic phosphorus and cholesterol of the blood are raised in nephritis; the former, especially in azotæmic and the latter chiefly in hydræmic nephritis. The blood phosphorus is said to give a better indication of prognosis than the blood urea; figures above $8 \mathrm{~m}$.gms. per cent., suggesting impending uræmia.

A mild acidosis is frequently present in nephritis, and in the late stages of azotæmic nephritis this may be severe. It is due partly to retained phosphate and sulphate, and, contrary to what occurs in diabetic acidosis, the ammonia coefficient of the urine is not raised so that renal acidosis cannot be detected by urine examination. It is best demonstrated by an estimation of the alkali reserve of the blood. According to A. A. Osman, the administration of alkalis to hydræmic cases with even slight acidosis results in a decrease of œdema and albuminuria. But the consensus of opinion is, that no permanent benefit results from intensive alkali therapy. In the severe acidosis of advanced azotæmic nephritis, alkali treatment may cause some temporary improvement, but a fatal outcome is not long delayed.

The excretion of phenol-sulphone-phthalein has also been used as a renal efficiency test, $6 \mathrm{~m}$.gms. of the dye being injected intramuscularly. The urine is collected one and two hours after the injection and made alkaline with caustic soda. The crimson colour is compared with that of a standard solution of the dye (dissolved in urine collected before the intramuscular injection). If the total volume of the urine, and its relative strength is known, the number of milligrammes of dye 
excreted can be calculated. Normally $60-85$ per cent. of dye is excreted in two hours, and an excretion of less than 50 per cent. is definitely pathological. This test gives results which parallel the urea concentration test.

Cardiac Failure.-In this condition, the urine urea is usually normal or high. As, however, the volume of urine excreted is diminished, the blood urea sometimes shews a moderate rise seldom exceeding $70 \mathrm{~m} . g m s$. per cent. The volume of urine passed in a day is the best indication of renal efficiency in cardiac failure.

Dehydration.- In the dehydration of infantile diarrhœa, the urine is of small volume owing to loss of fluid, but it is concentrated and its urea content is high. Diminished urine volume results from loss of fluid and is due to a decrease in the volume of the circulating blood in general and of the renal circulation in particular. Thus in spite of the relatively high urine urea the absolute amount of urea excreted is small and a marked rise of blood urea, sometimes exceeding Ioo m.gms. per cent. may occur. In cardiac failure and dehydration, therefore, high blood urea occurs with oliguria and a high urine urea, while in azotæmic nephritis, on the other hand, a raised blood urea is associated with polyuria and a low urine urea.

Surgical Conditions.- - Renal tests attain their chief significance in surgical conditions. As a preliminary to nephrectomy (e.g., tuberculous kidney), estimation of the blood urea is of the greatest importance, for if it be above $50 \mathrm{~m}$.gms. per cent. deficient renal function is indicated. The disease is then probably bilateral and presumably so extensive as to preclude operation.

In enlargement of the prostate, figures below $60 \mathrm{~m} . \mathrm{gms}$. per cent. suggest that suprapubic cystotomy with immediate prostatectomy should be undertaken. But if the blood urea is above $70 \mathrm{~m} . \mathrm{gms}$. per cent., operation becomes unsafe and efforts should be made to reduce toxæmia by diet, catheterization, etc. Failing this, cystostomy alone should be performed and the relief of back pressure on the kidneys may cause the blood urea to fall below $60 \mathrm{~m}$.gms. per cent., when prostatectomy may be carried out at a second operation. But if the relief of back pressure does not cause much decrease of blood urea, after several weeks, it is probable that permanent damage to the kidneys has resulted and prostatectomy may have to be omitted.

In unilateral renal disease important information may be obtained from separated samples taken after catheterization of the ureters. Thus, if the specimen from one side contains pus, while that from the other side is normal, the former specimen comes from the side of the lesion. Similarly, if one kidney secretes a urine containing 2 per cent. of urea, and the other only 0.5 per cent., the latter organ is the one chiefly affected. Frequently, the comparative excretion of dyestuffs is employed. An intramuscular injection of indigo-carmine is given and in unilateral disease much less dye is excreted by the damaged kidney. With normal function, excretion begins in 5 to 20 minutes, attains a maximum in about 45 minutes, and is complete in I2 to I4 hours. In bilateral renal disease, these manifestations are delayed; and in unilateral disease they are delayed on the corresponding side. Occasionally, delay in excretion may result from spasm of the ureter. This delay may be unilateral and persist for as long as half an hour. Phenol-sulphone-phthalein may be used in place of indigo-carmine, the excreted urine being received into alkali to develop the colour of the dye. Excretion begins 
in about 5 minutes, is maximal in 15 to 20 minutes and is complete in about 4 hours. This dye may be used as a time test, or as a quantitative test for each kidney separately.

Intestinal obstruction.-In intestinal obstruction and pyloric stenosis blood urea is often raised and may be as high as in uræmia. The kidneys are probably not implicated to any great extent and the cause is not clearly understood. These patients are poor operative risks, but the intensive administration of fluid and sodium chloride in the form of normal saline relieves dehydration, decreases the blood urea, diminishes alkalosis and increases blood chloride, thus rendering the patient more fit for surgical treatment.

In obstetric practice blood urea estimations are used in the differential diagnosis of albuminuria. If this condition is the result of pregnancy toxæmia the blood urea usually shews little change and high values, above $50 \mathrm{~m}$.gms. per cent., suggest that the albuminuria is due to an exacerbation of a pre-existing nephritis and hence the prognosis is less satisfactory.

\section{Conclusion.}

It has been seen that a clinical investigation and an ordinary urine examination must always precede special urine tests for renal function.

Of these special tests the blood urea and urea concentration tests are most important, but both will be negative unless renal damage is extensive and both are misleading in nephrosis; it is probable that they should be superseded by Van Slyke's Clearance test. Estimation of cholesterol is useful in albuminuria of doubtful nature, while excretion of dyestuffs is employed in surgical conditions. The other tests mentioned, though of great intrinsic interest, are not essential to the clinician in the diagnosis and treatment of renal disease.

\section{INTRACRANIAL ANEURISM.*}

\section{By C. ALLAN. BIRCH, M.D., M.R.C.P., D.P.H., Physician, North Middlesex County Hospital.}

Intra-cranial aneurisms are not at all rare although it is only in recent years that much attention has been paid to them. Most practitioners have met with an occasional case so that it is not surprising that in this hospital with a large number of acute cases we should have had four examples in the last few months. The frequency of intra-cranial aneurism is indicated by the fact that Fearnsides ${ }^{1}$ found that at the London Hospital between I907 and I9I3 there were 44 cases of intra-cranial aneurism in 5,432 post-mortems of the head-i.e., in 0.80 per cent. Busse $^{2}$ says that small aneurismal dilatations on the anterior communicating artery occur in as many as ro per cent. of all post-mortem specimens. Intracranial aneurisms most frequently cause symptoms between the ages of 25 and 40, but may do so at any age.

* A Post-Graduate lecture delivered at the North Middlesex County Hospital on June 20 th, 1934. 